\title{
Gestalt as an Emergence of Knowledge at Schools
}

\author{
Masoud Niati ${ }^{1, *}$ \\ ${ }^{1}$ Faculty of Education, Social Institute, University of Kocaeli, Izmit, Turkey \\ *Correspondence: Faculty of Education, Social Institute, University of Kocaeli, Izmit, Turkey. E-mail: \\ masoud.niati@gmail.com
}

Received: September 15, 2016

Accepted: Oceober 18, 2016 Online Published: January 25, 2016

doi:10.5430/sass.v4n1p32

URL: http://dx.doi.org/10.5430/sass.v4n1p32

\begin{abstract}
What is emphasised in this analysis is that the awareness of Gestalt by school principals and teachers can be utilised for implementing knowledge management strategies. Since one of the challenges to implement knowledge management is lack of transparency and how to transform synergy into innovation as well, it is assumed that Gestalt-oriented approach will help this lack of transparency diminish, and that synergy can turn into innovation. This work also tries to get an organized representation of how teachers and managers can consciously apply Gestalt qualities at schools in conjunction with knowledge management. First, a broad definition of Gestalt theory in the fields of psychology (in accordance with Christian Von Ehrenfelsin and Weithermar) will be given. Then a very brief philosophical depiction of Gestalt (by Heidegger) will be considered. After depicting the qualities of Gestalt, its supposed values and conceptions will be brought into a couple of frameworks (represented in figures 1 \& 2) among teachers, managers, family and society. Finally, at the end of this analysis, it is suggested that knowledge can be gained by Gestalt qualities and there can possibly no difference between knowledge creation and emergence of Gestalt at schools.
\end{abstract}

Keywords: Gestalt qualities, Gestalt theory

\section{Gestalt as a Cognitive Theory}

The findings of two meta-theories of Gestalt and System theory at the beginning of the last century have had their own effects on different fields of social sciences. These two fields, which deal with fundamental questions about systems, give really useful hints about what an organization, in this case a school, essentially is (Stephanie Harung, 2014). The radical ideas that Gestalt psychology provides include visual perception, and cognitive neuroscience such as those which are found in processing of information (Wageman, 2012). Gestalt theory was first defined by the Austrian philosopher “Christian Von Ehrenfelsin” in 1890. He sketched two types of form qualities including temporal qualities as processes taking place over time such as a melody, and non-temporal qualities such as a triangle. Next, Ehrenfelsin's qualities were applied by psychologists to describe human psychology. Max Wertheimer, Wolfgang Kohler, and Kurt Koffka began Gestalt psychology in Berlin in 1912 (Wagemans, 2012; Kohler, 1997). The focal point of their study was based on visual perception, on the interpretation individuals had toward clustered smaller objects within large objects, shapes- and they found that the whole is perceived differently from its components, in another terms, Gestalt is the dominance of the whole over the parts, it is a certain configuration of parts, their relations and interactions in order to make an individual perceive it as a whole. Max Wertheimer proposed that an individual tries to see himself in regard with a society in which he finds himself in a mutual relationship with other members of a community. Kohler observed that the specific functionality of a single component in regard with other components is perceived by its location to other parts, and he furthered it by giving the example of a corner in a rectangle and its relation to other lines. In his paper "physical Gestalten" (1920), Wolfgang Kohler put the idea of "Gestalten" as a "whole phenomena" making the difference between the whole perception and its consisting elements. Accordingly, the predominance of the whole over individual parts was discussed by Wertheimer in his study "organization of perceptual forms" (1923). All in all, Gestalt theories can be categorized into two major forms of "whole quality", and "components qualities. From then on, Gestalt psychologists have been studying on individuals' subjective experience and the organization of their perceptions in different contexts. By Gestalt quality, each two entities or objects is represented as a whole, and parts are different 
from the whole. Perceptual quality conceptualized on the relationship between the parts and the whole is identified in a scope of shapes, semantic meanings, music and storytelling (Perls, F.1973; Sabar, 2013). Organizational forms including "structure, figure and dynamic forces are some major components of Gestalt qualities in which structures, figures are defined as a configuration between parts and the whole. Based on Wertheimer's perceptual forms (1997), there are seven major ways, within organization of a form, taking place among objects, first, the proximity factor that describes the objects close to each other in a row or column belonging to one group or set, secondly, the similarity law tries to put and manifest identical objects next to each other, third law interprets the conflict among various occurrences of a factor resulting in a common fate. Fourthly, the law of simplicity describes the fact that there is a tendency to put more complex objects into simple arrays. In the fifth place, the direction factor is put and described as a tendency to follow the main line. The factor of closure is more like filling the gaps between objects next to each other. And finally, the good curve factor is the continuation of one line to another.

Multiple Gestalt organizational forms can occur in a variety of situations providing a group or a paradox (Wertheimer, 1997). The effects of memory and being familiar with a shape or object were the expanded principles on Wertheime's Gestalt qualities which were developed by Gottschaldt (1997). He conducted experiments focusing on the familiarity aspect of a shape or form in the memory by which individuals can recognize the alreadyrecognized shape in a larger container by a $0.6 \%$ increase of recognition.

According to Koffka (1935), the fundamental gestalt theory lies within the logistic approach rather than the sum of its components. The expanded theory of Gestalt claims that the mind has a tendency to simplify and at the same time unify complex phenomena by configuring a sort of regularity orders of forms and shapes (Wertheimer, 1923-1938). From this unification, the law of PRÄGNANZ (the minimum principle) was developed suggesting that the mind (or neurological brain) has a tendency to perceive the simplest and steadiest visual form. Accordingly, Gestalt psychology considers the mind or brain as a holistic area carrying self-regulatory "tendencies" (Gibbs, 1988). The desire to find structures in perceptual configurations and reconsidering the subjectivity of experiences has attracted contemporary scientific researchers (Wageman, 2012). Besides, according to Lacan (1949):

".... the total form of the body by which the subject anticipates in a mirage the maturation of his power is given to him only as a gestalt..." The point which Lacan makes is that the libidinal dynamism moves toward a mirror which acts like a "penumbra of truth". When the subjects unites with this mirror, they reach a whole.

Gestalt has different interpretations in regard to Gestalt philosophy, and Gestalt therapy. Accordingly, Fritz Perls (1973) invented the Gestalt therapy, and also techniques such as the "empty chair", Mono drama”. It should also be mentioned that Gestalt therapeutic pedagogy and creativity have a mutual relationship facilitating learning. The purpose brought about by Gestalt therapy is to teach people to collaborate together and struggle to "complete unresolved problems". As life changes and brings with itself new obstacles, health is sought by self-directed, self-motivated and creative people (Woldt, 2014). Gestalt pedagogy (therapy) proposes that learning takes place in a self-based regulation consisting of holistic approach within a self-determined borders. Creativity, innovation, experience, and inspiration are some other by-products of Gestalt therapy (Woldt, 2014). Woldt believes that "Creating a Gestalt-based learning environment can take place by an invitation to learn not by order". He applies "paradox" to engage his clients by providing them with "anti-assignments". He furthers that paradoxical principles are able to facilitate learners' responsibility for their own experience and learning.

Having emphasized on Gestalt therapy, Woldt actualized a syllabus putting forward the idea that if learners tend to participate in a dialogue upon any given subject, they already need to have studied on the subject before. Moreover, in Gestalt's holistic approach, the difference between the therapist's own personal and his or her professional development should be recognized. The major elements of Gestalt pedagogy include (1): self-based manipulation, (2): tendency to follow a bigger photograph (whole); i.e., Squareness is only conceptualized when the consisting parts come together for forming a whole. (Sabar, S., 2014).

\section{Gestalt and Heidegger}

Gestalt is relational and can be defined as a method of existential phenomenology; the objects such as "thought, reality and perception" are linked to each other based on "self", and "surrounding context" (Yontef, 1993). The turning point here is that, according to Bernhardd Radolff (2007), both Husserl and Heidegger have used the terminology of parts and whole: 
"What is crucial to Heidegger's sense of the gestalt of an entity is its movement of unfolding into its own inherent limit and its simultaneous movement of withdrawal back into its arch of movement... And only what has gestalt, in Heidegger's understanding of the tradition, has being and has a future".

Heidegger, by Gestalt, struggles to show that gestalt can give a form (limited, and differentiated) to existence. Gestalt is not simply about perceiving sensual data but reaching forms, particularities, scattered in the site, in this case a school, and recognizing meaningful forms:

"What is given is always a theme (object) standing in a field-it never stands alone; relations of temporal or local proximity, of qualitative similarity, establish a Gestalt connection” (Radolff, P. 19, 2007)

Formlessness resulting from technology and modern life needs a form and hermeneutic phenomenology (mostly Heideggerian phenomenology) tries to acquire frameworks of lived experiences (Sloan \& Bowe, 2013). The idea of being(s) and the idea of site, the former is a lens through which the socio-educational aspect of Bildung takes its "form" and "differentiated shape", and the site wherein beings find themselves and unfold their self.

\section{Knowledge Management and Gestalt}

The holistic approach of education so as to fill the gap between physical and spiritual divide, by a reference to Gadamer phenomenology and John Dewey's cognitive theory, has recently taken importance by researchers such as Scott R. Webster as a "healing” (Webster, 2012). Levels of perfection is a quality which gestalt presupposes, as Ehrenfels (cited by Radloff, 2007) holds that the relative unity of part and whole makes an outline of levels of gestalt:

"Higher levels reflect an ascent in the degree of formedness, and this is a value for human feeling, and a value in itself....the inclusion of meaningfulness and expressivity signifies that the object appears within an historical, cultural horizon" (Radloff, 2007).

From the theorem above, it can be inferred that unity of students, teachers, and school manager-leaders is the relative unity of parts and whole. This unity has degrees and levels, higher the levels, higher the belonging feeling. A very broad and simple categorization of this unity is presented in the figure 1.

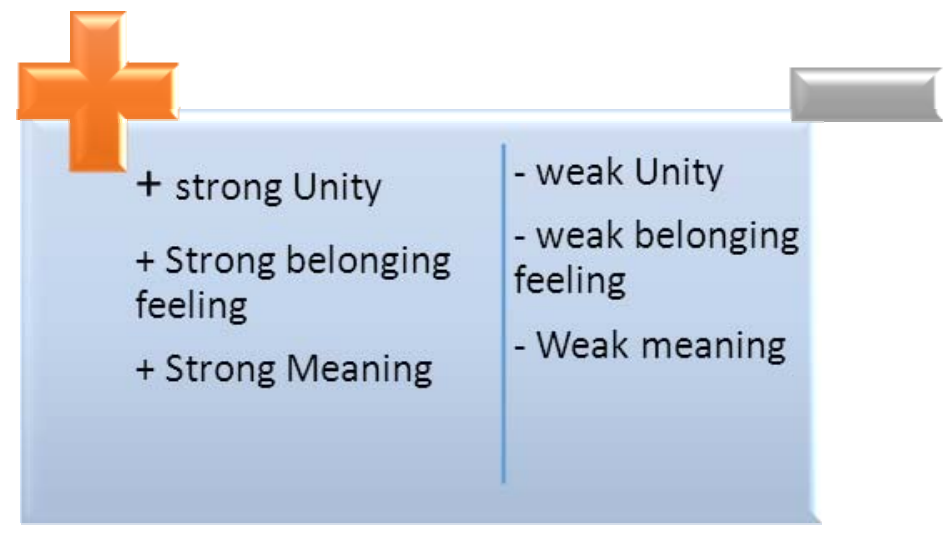

Figure 1. Gestalt Levels of Unity among Teachers, Managers, and Students

The question arises here is that how a good gestalt can be achieved through a school? The answer can be inferred from a definition provided by Kurt Goldstein.

"A good gestalt represents a very definite form of coming to terms of the organism with the world, that form in which the organism actualizes itself, according to its nature, in the best way"( cited by Radloff, p.17, 2007).

This actualization of self can take place in different forms and in different context. The following figure makes an attempt to manifest a unity between parts and the whole in the different sites such body, family, school, and finally society. The wholes which are not only the sum of members but have their own forms and meanings. 


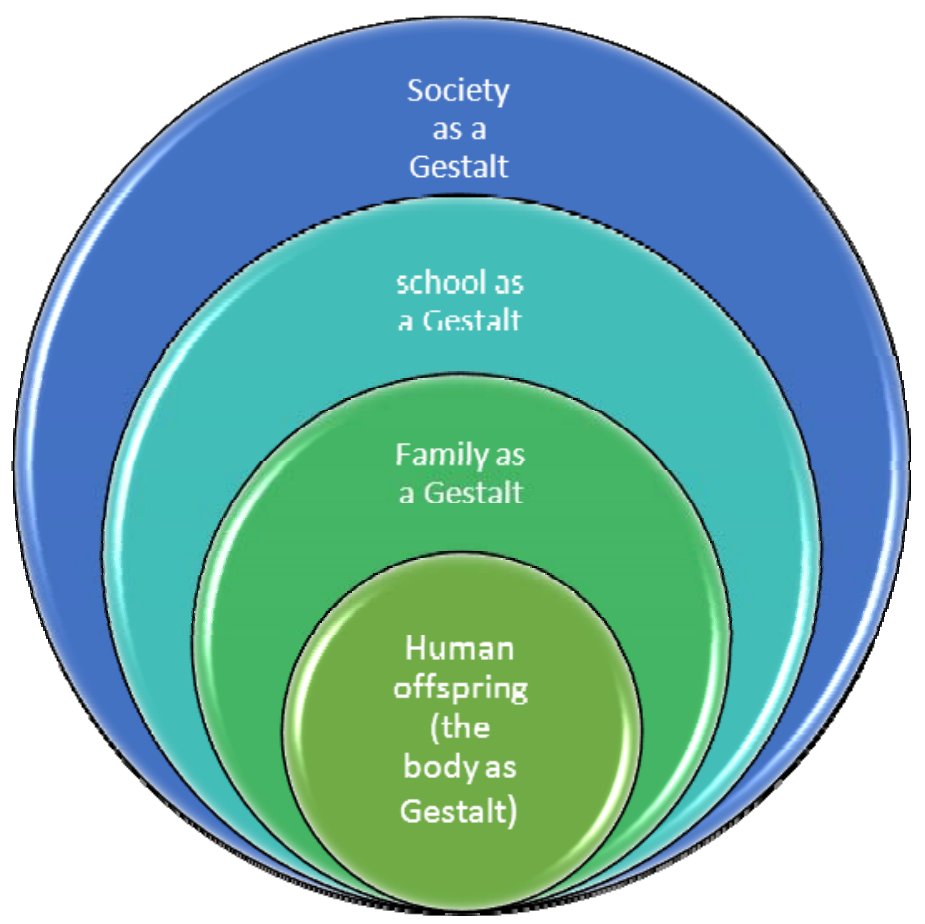

Figure 2. Gestalt Levels

Supposedly, Gestalt helps the realization of knowledge management take place faster. In other words, Gestalt can be seen as a real psychological tool for implementing knowledge management in schools. If teachers and principals know that they are inevitably part of a whole which is closely connected to them, the achievement of a goal would not be that difficult. Presumably, when teachers and principals know their own role in that whole, the degree of burn-out, distrust, and inequality feeling will be reduced.

Here, as Klaus North and Gita Kumta (2014) assume that the challenge is "to evolve the right approach for managing knowledge". Looking at Nonaka and Takeuchi formulation of knowledge management, it is obvious to notice that how close their definition of knowledge management is to the way Gestalt looks at school:

"By organizational knowledge creation we mean the capability of a company as a "whole" to create new knowledge, distributed through the organization and embodied in products, services and systems (Nonako \& Takeuchi, 1995)".

Furthermore, on the SECI model, the four basic rules which individuals are required to pass such as "internalization" shows Gestalt view and system theory lying at the background of the entire group. Gestalt draws attention to the background of people with different values who come together, work together and can inspire together to reach a shared vision/ solution/decision. It is the psychological description of an organization-school. What both knowledge management and Gestalt view promote is that the goals and values of a school considered as a whole in regard to teachers' behaviours and school values. Either short term success or long term progress have an emphasis upon the company (school) as a whole (Klaus North, Gita Kumta, 2014). All the corporate values, mission, vision and other reward systems finally contribute to the advancement of school as a whole.

"Management and reward systems should be reformed so that learning and competence development oriented at the overall goals of the organization are honoured" (Klaus North \& Gita Kumta, p. xxv, 2014).

When teachers' experiences, which themselves are a kind of gestalt because every experience is the meaning or form obtained through a sum of perceptions, juxtaposed for consideration by a school manager-leader, an innovation is born, a new value is reached, and finally a decision is taken by the whole. 


\section{Conclusion}

Applying the findings of Gestalt psychology, in appropriating KM (knowledge management) can have its own effect on educating teachers in a better way. By this, it is hoped that many disadvantages of working at schools would be reduced such as burn-out level, distrust in system, and the negative energy emerging from routine predictable workload. On the other hand, the most important advantage of implementing Gestalt is that problems arising at schools can be solved collectively, and seen as a whole. Manager-leaders of school can presumably keep teachers, and students feel belonging to the whole and equal. Thus, it is believed that feeling of inequality, discrimination, burn-out, and drop-out would be reduced. By analysing managers and teachers' views, the existence of "Gestalten subliminal configurations" can be considered, and it is supposed that by understanding teachers' conceptual methods, school managers can utilize their comprehension as well for designing a better curriculum at schools.

\section{Further Discussions}

As technological dimensions, cultural, personal conflicts spread in a non-stop fashion, and educational studies develop in accordance with leadership, further studies should be done on individualism and collectivism with(out) antagonism, and accordingly there is a need to have a coherence so as to keep interdisciplinary studies going on for building epistemological "pillars" of Educational management ( the term "pillar" is borrowed from Scott Eacott's work " A Theory and Methodology for Educational Leadership, Management and Administration, 2015).

\section{References}

Eric C. K., Cheng. (2015). knowledge management for school Education. springer publications,.

Evans, J., Rich, E., \& Davis, B. (2010). schooling the body in a performative Culture, the Routledge international Handbook of the sociology of Education.

Gibbs, G. (1988) learning by doing: A guide to teaching and learning. London: Further edition unit (cited in Ian Jackson's Gestalt - A learning Theory for Graphic Design Education, the Author Journal Compilation, Blackwell Publishing LTD, 2008.

Gottschaldt, k., Gestalt Factors and Repetition, Psycholology. Forsch., pp. 110-120 1926, translated in English by Ellis, willis D., A source book of Gestalt Psychology with an introduction by Kurt Koffka, published by: the Gestalt Joural Press, Inc, 1997

Hartung, S. (2014). Gestalt im management, springer Publications.

Jackson, I. (2008). Gestalt - A learning Theory for Graphic Design Education, the Author Journal Compilation, Blackwell Publishing LTD, 2008.

Köhler, W. (1997). Physical Gestalten, Die physischen Gastalten in Ruhe und im stationaren, ., A source book of Gestalt Psychology with an introduction by Kurt Koffka, published by: the Gestalt Joural Press, Inc.

Lacan, J. (1949). The mirror phase as Formative of the Function of the I, Mapping Ideology, Edited by Slavoj Zizek, published by verso.

Michaelsen, E. Gestalt Algebra - A proposal for the Formalization of Gestalt.

North, K., \& Kumta, G. (2014). knowledge management, Springer texts in Business and Economics.

Perls, F. (1973). The Gestalt Approach \& Eye Witness to Therapy, Science and Behavior books Inc, 1973.

Radolff, B. (2007). Heidegger and the question of National Socialism, Disclosure and Gestalt, university of Toronto Press incorporated 2007.

Sabar, S. (2013). What's a Gestalt? Gestalt Review, 17(1), 6-34.

Sloan, A., \& Bowe, B. (2013). phenomenology and hermeneutic phenomenology: the philosophy, the methodologies, and using hermeneutic phenomenology to investigate lecturers' experiences of curriculum design, published online: 16 February 2013.

Von Ehrenfels, C. (1890). Über "Gestaltqualitäten". Vierteljahrsschrift für wissenschaftliche Philosophie, 14, 224-292. Cited in Historical and conceptual background: Gestalt theory by Johan Wageman, Laboratory of Experimental psychology, University of Leuvan, oxford University Press. 
Wagemans, J. (2012). Historical and conceptual background: Gestalt theory, Laboratory of Experimental psychology, University of Leuvan, oxford University Press.

Weber, R. Scott. (2013). Healing the physical/spiritual divide through a holistic and hermeneutic approach to education, School of Education, Deakin University, Burwood, Australia. International journal of children's Spirituality, 18(1), 62-73. http:/dx.doi.org/10.1080/1364436x.2012.755955

Wertheimer, M. (1997). A source Book of Gestalt Psychology, General Problems, section 1: Gestalt theory,; Special problems: pp. 2-10 Perception and organization Edited by Ellis, Willis D 1997, Gestalt Journal press, Inc.

Woldt, ED. D, Ansel. (2009). Gestalt Pedagogy, Creativity in Teaching. Gestalt Review, 13(2), 135-148.

Yontef, G. (2002). The relational attitude in Gestalt therapy \& practice. International Gestalt Journal, 25(1), 15. 